\title{
"Imagens Projetadas do Império" O Cinema Hollywoodiano e a Construção de uma Identidade Americana para a Política da Boa Vizinhança
}

Rodrigo Medina Zagni*

Resumo: Este trabalho tem como objetivo compreender o processo de instrumentalização política da industria cinematográfica nos EUA nas décadas de 1930 e 1940, no contexto de implementação da "política da boa vizinhança" para a América Latina. Nosso foco de análise é a vinda de agentes dessa política com a missão de construir, por meio do cinema, uma identidade única na qual coubessem latino-americanos e estadunidenses, no esforço defensivo para a guerra que se anunciava.

Palavras-chave: Cinema, Política, EUA, América Latina, Segunda Guerra Mundial.

Abstract: This work aims to understand the political instrumentalization of the movie industry in the USA during the 1930's and 1940's of the "good neighborliness' policy" implemented with Latin America. We focus the coming of American agents to Brazil whit the mission of constructing, through the cinema, an unique identity in which both Latin American and American could recognize themselves in advocacy of the war that was announced.

Keywords: Cinema, Policy, USA, Latin America, World War Two.

\footnotetext{
* Historiador graduado pela Faculdade de Filosofia, Letras e Ciências Humanas da Universidade de São Paulo e doutorando em Práticas Políticas e Relações Internacionais pelo Programa de Pós-Graduação em Integração da América Latina da Universidade de São Paulo - PROLAM/USP. E-mail: rodrigo.historia.usp@gmail.com. Recebido em 22/01/08 e aceito em 20/05/08.
} 
"Saudamos a todos da América do Sul

Onde o céu é sempre azul

Saudamos a todos amigos de coraçâo

Que lá deixamos, de quem relembramos ao cantar essa canção."

Edward Plumb**

\section{Introdução}

Cinema e ideologia, e cinema e política, são temas já largamente debatidos por uma extensa bibliografia, contudo o que pretendemos fazer aqui é discutir uma dimensão restrita dessas relações, num período chave para a reelaboração das concepçôes de utilização prática da linguagem fílmica.

Referimo-nos à década de 1930 e à Segunda Guerra Mundial, no qual as tecnologias para projeção, a estruturação dos estúdios, a proliferação de salas de projeção e a consolidação de um mercado como âmbito de circulação desses bens culturais desenvolviam-se em plena velocidade.

No que tange aos EUA - lar da hollywoodiana "fábrica de ilusóes" -, seu papel no sistema internacional ao irromper do conflito, o extenso debate entre isolacionistas e intervencionistas na arena política interna para demarcação de sua política externa, e a violenta conversão de um perfil político antipático para com as repúblicas latino-americanas (na vigência ainda dos protecionistas neutrality acts ${ }^{2}$ ) para a política de "boa vizinhança", re-configuraram não só as relações internacionais, mas as armas de projeção de sua imagem seguindo este novo perfil de política externa.

Nesse contexto o cinema foi uma importante arma para operacionalizar a mudança da imagem que as repúblicas latino-americanas haviam conformado dos EUA, a partir de um histórico de conflitos, intervencionismos e isolamento econômico de suas políticas para a América Latina, desde as guerras mexicano-americanas em 1848, até as leis de neutralidade dos anos 1930, passando pelo violento Corolário Roosevelt da Doutrina Monroe.

Nosso objetivo é compreender as políticas públicas que orientaram a produção cinematográfica nos EUA em relação à América Latina, e como

** Versos da música de apresentação do desenho animado "Alô Amigos", de 1942, de Walt Disney.

${ }^{2}$ Promulgados sob vigência do New Deal (1933-1937), tinham a finalidade de evitar um outro conflito armado de iguais proporções às da Primeira Guerra, criando impedimentos para o fornecimento de armamentos a outros países, além de outros entraves de caráter extremamente protecionista. 
essa produção se deu de fato.

Nosso objeto consiste nas relaçóes entre a Divisão de Cinema do "Escritório para Assuntos Interamericanos"3 e a produção cinematográfica nos EUA, cujo público-alvo era a América Latina.

Não trataremos da totalidade dessa produção, mas buscaremos empreender estudos de casos sobre os agentes dessas políticas, ligados ao cinema e envoltos no complexo jogo da nova política externa estadunidense.

Quais as políticas que orientavam essa produção cinematográfica? A quais interesses serviam e o que se pretendia a partir dos filmes? Como se relacionariam as obras acabadas com o mundo em guerra?

O esforço compreensivo destas questôes é de fundamental importância para lançar luzes sobre as relaçóes interamericanas, estando o evento relacionado a um contexto maior na complexa política externa dos EUA.

O esforço é justificado, pois a conformação de um núcleo de poder centrado na indústria cinematográfica estadunidense em suas relaçóes com a América Latina estabeleceu paradigmas ainda vigentes, guardadas as devidas proporçóes, nas relaçóes culturais interamericanas.

Com esse objetivo e sob esta justificativa analisaremos parte do expediente do Escritório para Assuntos Interamericanos, e parte da produção decorrente deste esforço.

À análise fílmica buscaremos associar uma análise social, focando os segmentos de sociedade, nas estruturas de poder, que se articularam para vocalizar seus interesses por meio deste veículo midiático de muito longo alcance.

Pretendemos demonstrar que o contexto de guerra mundial acompanhou no cinema não só sua instrumentalização como bem simbólico e veículo comunicacional, como arma de propaganda de guerra voltada à cooptaçáo e ao aliciamento aos valores estadunidenses; mas que no mesmo período estabeleceram-se mercados para sua circulação, o que foi fundamental não só para a construção e projeção das imagens do império, mas para a circulação

\footnotetext{
${ }^{3}$ Criado em 1940 foi inicialmente designado Office of Inter-American Affairs ou Office for Coordination of Commercial and Cultural Relations between the American Republics (OCCCRBAR), em 1941 foi renomeado como Office of the Coordinator of Inter-American Affairs (CIAA) e em 1945 como Office for Inter-American Affairs ou Office of the Coordinator of Inter-American Affairs (OCIAA). Funcionou de 1941 a 1946, com sede em Washington, DC (EUA), e teve como finalidade gerenciar as políticas estadunidenses para a América Latina, no âmbito econômico, político e cultural.
} 
e re-elaboração desta imagem, hegemônica no hegemônico "cinema americano", nas décadas que se seguiram ao término do conflito.

\section{Desenvolvimento}

\section{O papel da mídia na guerra}

A cientista social Maria Sylvia de Carvalho Franco ${ }^{4}$, na polêmica discussão que travou com o crítico literário Roberto Schuwarz 5 , colocou o problema da "circulação de idéias" por meio da indústria cultural da seguinte forma:

a circulação de mercadorias e sua absorção pelos países dependentes ou atrasados é inerente à natureza dos mercados internacionais, isto é, se explicam pela divisão do trabalho social. Mas como se realiza a circulação de idéias? Pela via de uma indústria cultural dos centros hegemônicos que criaria e determinaria seus consumidores, suas preferências intelectuais e seu gosto? (FRANCO, 1976, p. 72)

A resposta que encontramos em relação ao período da Segunda Guerra Mundial, no âmbito das relaçóes interamericanas, é positiva neste sentido, e afirma a política do governo de Frankiln Delano Roosevelt ${ }^{6}$ (1882-1945), por meio de seu "Escritório para Assuntos Interamericanos", de disseminar a imagem dos EUA como o púlpito da liberdade e de seu conceito (próprio) de democracia como a única saída possível frente ao perigo nazista. Uma ação de conquista de coraçóes e mentes que retomava a problemática lógica do Destino Manifesto 7 num novo contexto.

\footnotetext{
${ }^{4}$ Professora dos departamentos de Filosofia da Universidade de São Paulo e da Universidade Estadual de Campinas.

${ }^{5}$ Foi professor de Teoria Literária na Unicamp.

${ }^{6}$ Presidente dos EUA, exerceu mandato de 1933 a 1945.

${ }^{7} \mathrm{O}$ primeiro a utilizar o termo foi o jornalista nova-iorquino John L. O'Sullivan, na revista Democratic Review, no ensaio intitulado "Annexation", de agosto de 1845 (texto disponível no sítio: http://web.grinnell.edu/courses/HIS/f01/HIS20201/Documents/OSullivan.html) em que defendia a anexação do Texas pelos EUA: "Nosso destino manifesto atribuído pela Providência Divina para cobrir o continente para o livre desenvolvimento de nossa raça que se multiplica aos milhões anualmente." O Destino Manifesto portanto expressa a crença de que o povo dos EUA teria sido eleito por Deus para liderar o mundo, e que portanto a sua expansão seria, além do cumprimento desse desígnio divino, uma tarefa manifesta e inevitável. Tornou-se doutrina política durante a segunda metade da década de 1840, incluindo a compra de Gasden e do Alaska no expansionismo que tinha como direção o norte. Caiu em desuso em 1850 e foi retomada em 1880 para legitimar
} 
Não se trata apenas de disputa por mercados, num contexto bélico a finalidade passou a ser política e no final das contas militar: a cooptação ideológica no esforço de guerra, o que por sua vez garantiu aos EUA liderança absoluta nesses mercados, o meio de circulação de idéias e ideologias como bens de consumo de massa.

Como produto acabado do capitalismo, como um bem de consumo de massa, o cinema hollywoodiano tinha compromissos políticos e ideológicos e se articulava diretamente com a política externa dos EUA.

$\mathrm{Na}$ viragem de um ciclo sistêmico do capitalismo sob hegemonia britânica para a estadunidense, o epicentro do caos sistêmico foi indubitavelmente o período da Segunda Guerra Mundial, e para o estabelecimento e a consolidação desta nova hegemonia o novo império contava com uma nova arma.

Para o sociólogo Emir Sader ${ }^{8}$ "nenhum instrumento foi tâo importante para essa hegemonia do que Hollywood" (SADER, 2006, p. 1).

Contudo o professor aponta um aspecto inusitado se pensarmos o cinema, nos EUA, como arma de guerra no contexto da Segunda Guerra Mundial, uma vez que a indústria cinematográfica hollywoodiana, à exceção do caso de Chaplin com o filme "O grande ditador", não se bateu frontalmente com o nazismo. Veremos que o cinema hollywoodiano foi instrumentalizado numa estratégia defensiva, na qual o alvo era a América Latina, não ofensiva, motivo pelo qual o alvo não foram inicialmente os nazistas, tão somente referidos.

\section{A mídia nas relações interamericanas}

No que tange às relaçóes entre EUA e América Latina, a própria disparidade econômica, perceptível por meio da invasão de produtos simbólicos e tecnologias a preços relativamente acessíveis ao consumidor mediano, corroborou para o estabelecimento de um estado contemplativo por parte do espectador/consumidor latino-americano.

$\mathrm{O}$ yankee era o produto acabado da modernidade, o auto-intitulado

dessa vez o expansionismo para além das fronteiras dos EUA. Como ideologia, uma crítica via de regra externa aos círculos acadêmicos atribui a doutrina como o motriz do que chamam de "imperialismo norte-americano".

${ }^{8}$ Professor da Universidade de São Paulo (USP) e da Universidade do Estado do Rio de Janeiro (UERJ). 
"irmão mais velho" da América Latina, e essas convicções circularam agregadas a objetos tridimensionais ou a produtos imateriais, como os filmes de Hollywood ou as propagandas de cigarros.

O fenômeno da atração cultural estadunidense já era perceptível pelo menos desde o final do século XIX, conforme atesta uma significativa literatura que pensava questôes identitárias referentes à influência modernizadora dos EUA - é o caso de "Ariel” (RODÓ, 1947), do escritor uruguaio José Enrique Rodó (1872-1917) -; mas na década de 1930 a penetração cultural ostensiva em direção à América Latina, com a difusão do "american way of life", tratava-se de uma estratégia multideterminada mas com um fortíssimo viés político, como política de Estado.

Nesse sentido mobilizou-se no período a produção cinematográfica e radiofônica, além da mídia impressa, esta de menor alcance.

Durante o período de vigência da neutralidade inicial americana na Segunda Guerra Mundial, a cooperação que os EUA esperavam do Governo das repúblicas latino-americanas ia além da entrega de bases militares e navais em sua geoestratégia defensiva: havia uma guerra ideológica já em curso. A guerra contra o Eixo já aparecia no horizonte dos EUA a ponto de movimentar os esforços de sua diplomacia e demais agentes de política externa para uma intensa atuação na construção de uma solidariedade hemisférica, o que ocorreu mais incisivamente com a propagação dos valores pan-americanos durante as conferências pan-americanas? .

Esta nova atuação de caráter internacionalista impunha também novos desafios à política externa dos EUA. Com uma guerra ideológica já em curso desde a conversão de sua política externa isolacionista para o intervencionismo, e para além da diplomacia e dos tratados de cooperação militar, a cultura constituía um novo front.

Era preciso engajar-se nesta frente, desenhando estratégias de ataque e mecanismos de defesa eficientes.

A escolha foi defensiva para os EUA, mas tomou a América Latina ofensivamente na estratégia de sua cooptação.

No espectro político as correspondências diplomáticas que circularam

\footnotetext{
${ }^{9}$ Mais especificamente, referimo-nos à VIII Conferência Pan-americana, realizada em Lima no ano de 1938; IX Conferência dos Estados Americanos em Bogotá, em 1948; e às reuniões extraordinárias de Ministros de Relações Exteriores: no Panamá, em 1939; em Havana, em 1940; no Rio de Janeiro, em 1942; e no México, em 1945.
} 
nos primeiros anos de guerra, entre EUA e Brasil, denunciavam uma extrema preocupação com a opinião pública latino-americana, instruindo-se o governo brasileiro a adoção de medidas coercitivas a qualquer tipo de crítica que fosse feita à política estadunidense.

Segundo correspondência do tenente-coronel Lehman Miller, chefe da missão militar dos EUA no Brasil, ao chefe do Estado-maior do Exército Brasileiro,

[...] o auxílio que se deseja do Brasil, caso se torne necessário a passagem através de seu território de forças dos Estados Unidos para ajudá-lo ou a qualquer outra nação é como se segue: a) - proporcionar ( . . . facilidades ( . . . ) a medida que a situação o exija; b) - mobilizar a opinião pública no sentido de facilitar o auxílio prestado pelos Estados Unidos e dissuadir qualquer ataque que por ventura possa ser feito pelo rádio ou pela imprensa sobre "imperialismo ianque" etc. (Correspondência do tenentecoronel Lehman Miller ao chefe do Estado-maior do Exército Brasileiro, datada de 19 de setembro de 1940, apud SILVA, 1975, p. 79)

O aparelho estatal de controle à imprensa, rádio e cinema brasileiros, o $\mathrm{DIP}^{10}$ do Estado Novo ${ }^{11}$, deveria estar desta forma alinhado às políticas dos EUA, como um instrumento fundamental da aproximação que se pretendia entre seus governos.

\section{O OCIAA}

Nos EUA este tipo de controle foi mais eficientemente exercido após agosto de 1940, com a criação do "Office of the Coordinator of Inter-American Affairs (OCIAA)", órgão diretamente ligado ao "Conselho de Defesa Nacional" do governo dos EUA.

O escritório era chefiado pelo empresário Nelson Rockfeller e tinha como objetivo elaborar e desenvolver projetos de aproximação entre EUA e América Latina. Suas divisões contavam com setores de relações culturais, comunicaçóes, saúde e relaçóes comerciais e financeiras, cujas seçóes por

\footnotetext{
${ }^{10}$ Departamento de Imprensa e Propaganda, criado em 1939.

${ }^{11}$ Implantado por Getúlio Vargas em 10 de novembro de 1937.
} 
sua vez subdividiam-se nas áreas de música, cinema, imprensa, literatura, rádio, arte, finanças, exportação, problemas sanitários, transporte e educação infantil.

Foi construída rapidamente uma íntima relação entre o OCIAA e as três principais repúblicas latino-americanas no período, segundo seus próprios critérios: Brasil, Argentina e México.

No caso brasileiro a atuação ostensiva do OCIAA se deu com o apoio do DIP, que passaria a funcionar como uma espécie de continuação do escritório no Brasil, promovendo desde um intenso controle à imprensa e sua conversão para a exaltação dos valores estadunidenses, até a elaboração de cartilhas escolares e a implementação da obrigatoriedade do ensino do idioma inglês nas escolas.

A divisão de cinema, bem como as demais divisões que lidavam com informações e comunicações, tinham como diretriz a elaboração e difusão de imagens agradáveis associadas a tudo o que viesse dos EUA. Eram promovidos desde bens de consumo de massa como refrigerantes, cigarros e indumentária, criando hábitos para o seu consumo; até valores e costumes, como o uso corrente de expressóes no idioma inglês e comportamentos padronizados que denotavam e definiam um novo modelo de alta cultura destinado às classes médias e altas, enquanto os hábitos culturais nacionais e tradicionais passavam a denotar as classes de menor poder aquisitivo.

Apesar do cinema ter ocupado um lugar de destaque dentre as divisóes relacionadas à cultura e informação, os maiores esforços se concentravam na divisão de rádio, por conta de seu alcance e popularidade.

A guerra era coberta em tempo real pela rádio "A voz da América”, cujos estúdios e transmissores funcionavam nos EUA, gerenciados pelo OCIAA, mas cujas difusôes eram dirigidas ao território e públicos brasileiros, fundamentalmente jovens de classe média. Nos programas eram comuns os slogans exaltando o "estilo americano", conformando consenso e as convicções de seus ouvintes.

Não tão popular quanto o rádio, mas já largamente difundido como hábito das classes dominantes, o cinema foi o segundo grande veículo de comunicação no interesse do escritório.

Por meio dos estúdios de Hollywood os filmes de ficção e documentários 
produzidos durante as décadas de 1930 e 1940, em geral, faziam apologia ao modo de vida da classe média dos EUA, sob a orientação direta das políticas do escritório, conforme pode corroborar um intenso expediente de papéis governamentais que circulavam entre o OCIAA e os estúdios, com as diretrizes que deveriam ser seguidas nos roteiros dos filmes.

A estrutura organizacional que relacionava o OCIAA aos estúdios, e por sua vez aos roteiristas, produtores e diretores, pode ser verificada no documento redigido na oportunidade em que o então CIAA, por meio de sua Divisão de Saúde, produzia 24 curtas em parceria com o "Instituto Nacional de Cinema Educativo Brasileiro”. 
SET-UP FOR PRODUCING 24 SHORT SUBJECTS FOR

THE HEALTH \& SANITATION DIVISION OF THE

CIAA IN BRAZIL IN CONJUNCTION WITH THE

INSTITUTO NACIONAL DE CINEMA EDUCATTVO

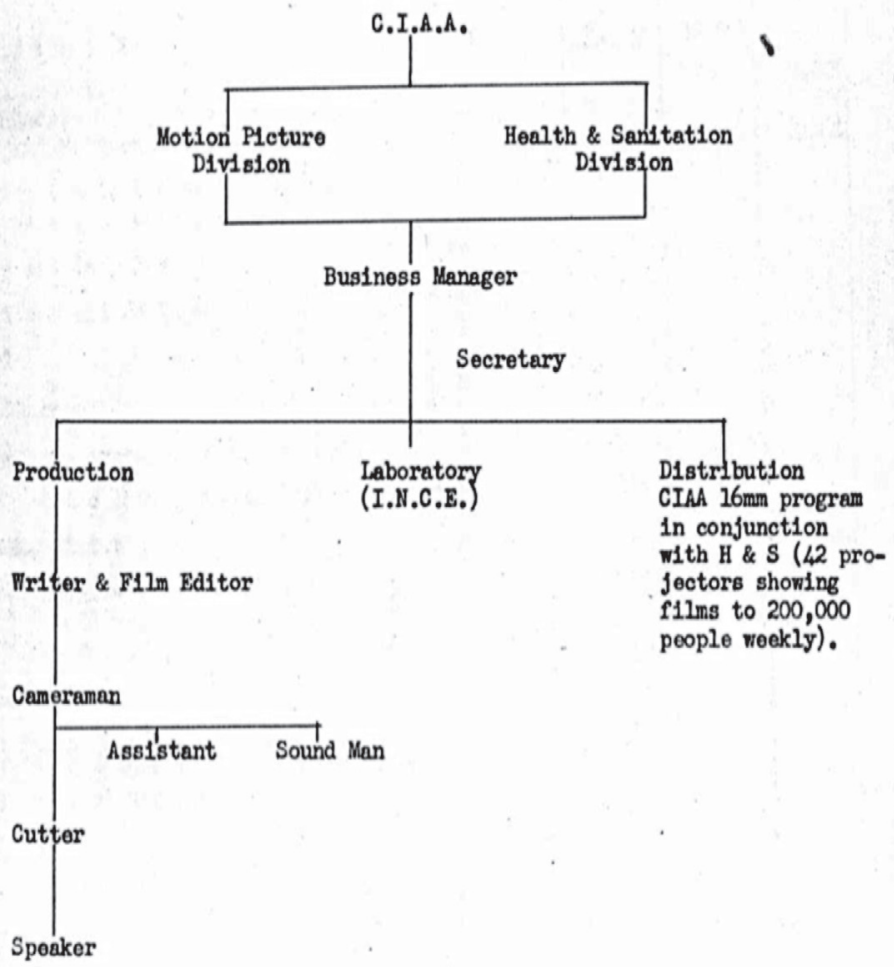

Quanto ao conteúdo dos filmes, as diretrizes constam em um trecho do documento produzido pelo "Coordinator Of Inter-American Affairs" em agosto de 1943 e dirigido à "Motion Picture Society For The Americas", que incluía entre outros estúdios a Paramount e a Metro-Goldwyn-Mayer:

it would likewise be very helpful to the general program if, when the occasion presents itself, material could be included in both 
features and shorts that will be helpful, if only in a small way, to the general purpose we have in mind. It might be possible, without any impairment of the entertainment quality of the films, to inject into the story an occasional scene, music, character, or line of dialogue, in thorough harmony with the spirit of the story, which will have its effect in contributing something to the over-all program. If, for example, a Latin American boy, or one with a distinctively Latin American name, could be included in, say a group of American soldiers fighting in the war, such a indication would be helpful. There are many such boys, from a number of the Latin American countries, now serving in the American Armed Forces, and to throw some slight emphasis on their activities, would be certain to please, at least, a part of the audience in Latin America. These minor incidents, inserted in American films, should serve in building up an accumulated favorable impression in the minds of those who see our pictures in Latin America. (grifos nossos)

Houve também um imenso cuidado para que os filmes, ao exaltarem os valores, usos e costumes estadunidenses, não denegrissem de alguma forma o que entendiam como cultura e modo de vida latino. Isso obrigou à adoçáo de uma nova conduta por parte dos roteiristas e produtores, por exemplo, nos westerns tão populares naquele período, em que os "foras da lei” não poderiam mais ser mexicanos, a fim de evitar qualquer tipo de mal estar que pusesse em risco as novas políticas culturais de cooperação.

Quanto à questão de gênero, sociedades notadamente machistas como as hispano-americanas naquele período foram referidas por meio da exaltação à virilidade dos latinos e à sensualidade das latinas, ambos estereotipadas.

Carmem Miranda, a portuguesa que se tornou estereótipo da cultura brasileira, é um exemplo clássico da construção identitária que se deu, de forma exógena, em torno da mulher latino-americana: a selvagem que arranhava homens civilizados maravilhados por sua sensualidade e exotismo.

O inevitável envolvimento dos EUA na guerra, após um longo embate entre isolacionistas e intervencionistas na arena política interna, como resultado da vitória do poder executivo no Congresso, refletiu diretamente nas políticas culturais dentro e fora dos EUA, e com isso nas políticas sobre a utilização do cinema como instrumento de cooptação ideológica. 
Neste novo momento o filme de Chaplin se tornou arma de propaganda antinazista do OCIAA na América, conforme demonstra o Memorandum CO-No. 1029, datado de 7 de maio de 1942 e endereçado ao coordenador do OCIAA, cujo título era "'The Dictator' film", onde se pode ler sobre os preparativos para sua primeira exibição no Brasil, que ocorreria em São Paulo, no dia 14.

Mas para que os filmes fossem realizados seus artífices precisavam previamente "mapear" o terreno até ali desconhecido: a América Latina. Além desta necessidade, a influência que esses agentes exerciam sobre a mídia e entre espectadores latino-americanos poderia ser utilizada para a promoção dos valores estadunidenses e para a ampliaçáo de seu poder e influência na América Latina.

$\mathrm{Na}$ lista de celebridades que visitaram a América Latina com este escopo estão as atrizes Lana Turner e Tyna Power, o diretor John Ford e os cineastas Orson Wells e Walt Disney.

Para cumprir nossos objetivos nos ateremos à visita destes dois últimos.

\section{Walt Disney vem à América}

Para que a política da boa vizinhança reorientasse uma nova política cultural o método utilizado foi a criação de personagens que concentrassem os traços característicos do que se pensava como uma identidade latinoamericana. $\mathrm{O}$ que de fato ocorreu é que nesses personagens estavam contidas as características do que os estadunidenses, que pouco ou nada conheciam da constituição cultural latino-americana (dada a oscilação entre isolamento e intervencionismo em sua política externa e a histórica ausência de cooperação) pensavam que fosse esta identidade. $\mathrm{O}$ produto final foram as caricaturas que já conhecemos.

Um dos principais agentes dessas políticas e criador de algumas dessas caricaturas, por conta de sua influência, era Walt Disney (1901-1966), responsável pelos personagens para cinema mais significativos desse processo.

Tratá-lo como um agente direto da política externa dos EUA não constitui nenhum tipo de conspiracionismo. Christophe Barbier (2001) e Marc Eliot (1993) demonstraram que além de ter sido simpatizante do nazismo, Disney 
foi ainda informante do FBI nos primeiros anos da Guerra Fria, tendo delatado atores e cineastas ao Comitê Parlamentar liderado pelo senador de Joseph McCarthy no auge da perseguição anticomunista nos EUA.

Ariel Dorfman e Armand Mattelart (1980) relacionaram sua produção diretamente ao fenômeno do imperialismo estadunidense, demonstrando que seus filmes serviram como instrumentos de uma política externa que disputava coraçóes e mentes, desta vez contra o comunismo.

Com isso não resulta difícil caracterizá-lo, Walt Disney, como fez o historiador Sidney Ferreira Leite, como um "agente especial da boa vizinhança” (2006), tendo sido indicado à Nelson Rockfeller pelo próprio presidente Franklin Roosevelt.

Sua vinda para o Brasil em junho de 1941, como agente do OCIAA com a missão de expandir e consolidar a política da boa vizinhança, marcou um momento decisivo para a expansão de seus estúdios. Tendo enfrentado problemas econômicos e inclusive uma greve de funcionários, Disney se via ainda em meio a acusaçóes da imprensa que o relacionavam ao nazismo.

A aliança com Rockfeller, nesse contexto, lhe era extremamente favorável. Acabava de receber do governo Roosevelt mais de 100 mil dólares para que produzisse duas peças de propaganda política, dois desenhos com um tema demarcado: a solidariedade entre as Américas; o que resolvia tanto os problemas econômicos quanto apaziguaria as notícias de que seria um colaborador do nazismo dentro dos EUA.

Todas as despesas de sua viagem, bem como de toda a equipe, foram pagas pelo governo Roosevelt.

O pretexto para a viagem era a busca de novos talentos e inspiração para novas obras, além da premiação que a crítica brasileira daria ao desenho animado "A Branca de Neve e os Sete Anóes" e a divulgação de sua nova obra, "Fantasia". Mas a agenda de Disney revela encontros com autoridades governamentais, como o próprio presidente Getúlio Vargas, e declaraçóes à imprensa, promovendo a integração continental sob a política da boa vizinhança, sob a liderança dos EUA.

O entusiasmo de Vargas após a visita de Disney e a disposição que manifestou em cooperar com o projeto de integração proposto pelos EUA, 
representava possibilidades de cessão das bases pretendidas pela geoestratégia estadunidense em Natal e Fernando de Noronha.

Disney ainda se encontrou duas vezes com o diretor do DIP, Lourival Fontes, no Cassino da Urca e na sede do departamento, no Palácio Tiradentes; demonstrando que os agentes do OCIAA conectavam as estratégias culturais dos EUA aos aparelhos de censura na América Latina.

De volta aos EUA, em 1942 os estúdios Walt Disney apresentam o desenho animado "Alô amigos!", onde o sisudo Pato Donald é transformado em uma espécie de "guia turístico" por uma viagem à América Latina, percorrendo rapidamente Bolívia, Chile, Colômbia, Peru e Venezuela, e prolongandose mais demoradamente no Brasil e na Argentina. O "recorte" sobre essas repúblicas é outro denotador importante para vincular o desenho como peça de propaganda do OCIAA, que privilegiava em suas políticas de aproximação o contato com Brasil, Argentina e México, países que aspiravam à liderança regional e exerciam enorme influência, como pólos irradiadores de cultura, em relação às demais repúblicas latino-americanas.

A viagem fantasiosa é o palco da criação do personagem Zé Carioca, o papagaio que ao ser colocado como o novo amigo do já célebre Pato Donald edificava no plano simbólico as bases para a influência cultural e política dos EUA na América Latina no plano real.

Os valores expressos no desenho corroboram a tese de que a produção seguia não só as diretrizes do escritório mas também a cartilha de recomendações do DIP. O tom nacionalista assumido na seqüência onde a cultura brasileira é reduzida simplificadamente no carnaval carioca e no "molejo" da baiana, é ambientada pela composição de Ari Barroso, "Aquarela do Brasil”, peça de propaganda por sua vez do Estado Novo.

A fórmula para o tipo de cooperação desejada: Zé Carioca, o brasileiro simpático, malandro, falador e indolente, amigo do sério e temperamental Pato Donald, o estadunidense. O irresponsável que precisava, nos tempos de crise, da liderança do responsável.

Para Sidney Ferreira Leite,

apesar de todos os cuidados da produção em não cometer erros para desempenhar de modo eficiente a missão diplomática traçada, as 
contradiçôes e as ambigüidades do desenho são explícitas. Donald e seus companheiros não se comportavam como amigos, mas como turistas que visitavam terras exóticas. O turista interpreta as culturas das regióes que visita como uma seleção de monumentos. $\mathrm{O}$ resultado de tal interpretação é a redução dos nativos a tipos, desprovidos de personalidade e história, isto é, estereótipos. No Brasil, por exemplo, o carioca é caracterizado como o malandro simpático e cordial, a síntese do "espírito brasileiro", o argentino é representado pelo vaqueiro gaúcho, aventureiro e corajoso. Em outras palavras, tipos que resumiam o olhar americano sobre seus vizinhos latinos, sem a intenção de observar as diferenças culturais, mas comprometido em reduzir e classificar, estratégias para submeter o desconhecido à condição de inferior (LEITE, 2006).

O segundo filme encomendado pelo governo Roosevelt foi lançado apenas em 1945, o desenho animado "Os três cavaleiros", que no Brasil recebeu o nome de "Você já foi à Bahia?". Nele a conjuntura do conflito armado, que já envolvia além dos EUA, o Brasil e o México, reflete na elaboraçáo de um novo personagem: o mexicano Panchito. Reflete também o distanciamento da política externa dos EUA da Argentina, por conta dos desentendimentos havidos nas conferências Pan-Americanas e sua relutância em reconhecer a hegemonia estadunidense na liderança continental; pela ausência de referências ao país que deixara de ser um bom vizinho, ao contrário do que acontece em “Alô amigos!”. Já Brasil e México, cujos personagens simbolizavam a fidelidade aos EUA, recebiam de volta sua amizade no plano simbólico no mesmo ano em que, no plano real, os dois países reconheciam oficialmente a hegemonia estadunidense e sua liderança hemisférica, consolidando o modelo do moderno sistema pan-americano vigente do pós-guerra até pelo menos a Guerra das Malvinas, em 1982.

A estrutura ideológica que dá sustentação ao desenho é a mesma do primeiro, ou seja, Donald é o turista em busca do exotismo, e a América Latina, encarnada pela Bahia, a terra onde os desejos são saciados pela natureza exuberante e pela sedução das mulheres, catalisadas pela baiana Iaiá, que seduz e beija o pato.

A integração é simbolizada pela dança de Donald que não resiste ao ritmo latino e se entrega aos fascínios da baiana. 


\section{Orson Welles vem à América}

O cineasta estadunidense George Orson Welles ${ }^{12}$ (1915-1985) esteve profundamente envolvido pelos processos políticos que levaram à implementação da política da boa vizinhança. Contratado pelo estúdio "RKO Radio Pictures Inc." - subordinado às políticas do "Escritório para Assuntos Americanos" e sua Divisão de Cinema -, para realizar um filme no novo perfil implementado, Welles enveredou para uma narrativa crítica dessas identidades, sendo demitido pelo próprio estúdio enquanto ainda realizava filmagens no Brasil.

Mas para entendermos a natureza do papel que desempenhou como agente dessas políticas é necessário compreender parte de sua biografia, que se confunde com a própria história da comunicação social.

Poucos eventos foram tấo significativos no sentido de demonstrar o poder de controle social dos meios de comunicação de massa quanto o "trote" pregado por Orson Welles na noite de Halloween de $1^{\circ}$ de novembro de 1938, quando dramatizou com imenso realismo a obra de Herbert George Wells, "A Guerra dos Mundos", narrando pela rádio CBS que a Terra estava sendo invadida por extraterrestres.

O pânico criado pela transmissão radiofônica tomou ruas, congestionou estradas e provocou a ira de pessoas que se armaram para enfrentar o perigo alienígena. Isso não só por conta da transmissão mas pelo imaginário instantâneo que a concebeu como realidade, tendo como base não apenas as narraçóes de Welles mas as imagens catastróficas amplificadas no imaginário coletivo e que instantaneamente se tornaram realidade para aqueles que ouviram a transmissão ou que souberam dela. Com riqueza impressionante de detalhes muitos a partir dali juravam ter visto evidências da invasão como, por exemplo, sinais de fumaça vindos do "local do ataque".

Não apenas um simples trote ou a demonstração do brilhantismo na dramatização de Welles, o evento marcou a ascensão de uma hegemonia midiática, de veículos de comunicação de massa voltados à construção da realidade e obtendo êxito como mecanismos de controle social.

O evento garantiu a Welles um milionário contrato com o estúdio RKO, de Hollywood, para dois filmes, com total liberdade para dirigir, atuar, produzir e escrever os roteiros.

${ }^{12}$ Além de cineasta foi também diretor, roteirista, produtor e ator. 
Em 1941 estreou no cinema como diretor, co-roteirista (junto de Herman J. Mankiewicz), produtor e ator, com a aclamada obra "Citizen Kane", considerada por grande parte dos críticos posteriores como um dos melhores filmes de todos os tempos ${ }^{13}$.

Citizen Kane inovava a própria linguagem fílmica, introduzindo novas técnicas ou técnicas raras e pouco utilizadas. Recursos até ali inexplorados como a profundidade do campo (campo e contra-campo), angulaçóes de câmera (plongée e contra-plongée), planos longos, ações entrecortadas num mesmo ambiente e narrativas não-lineares, que obrigavam Welles a um cuidado muito maior na fase de edição e montagem do filme.

A trama central de Citzen Kane era a vida de um magnata da área da comunicação, de sua ascensão à queda: o personagem Charles Foster Kane, interpretado pelo próprio Orson Welles.

$\mathrm{O}$ resultado final não foi bem recebido pelos estúdios de Hollywood. Polemizou-se a possibilidade de Welles ter se baseado na biografia de William Randolph Hearst, que por 40 anos foi o mais rico e poderoso homem da comunicação nos EUA ${ }^{14}$.

Ainda gozando do contrato firmado com Hollywood, Welles filmou Soberba, em 1942. Um retrato crítico da sociedade americana, com os mesmos recursos estilísticos de Citizen Kane, mas sem o mesmo sucesso de público ou clamor da crítica, ou mesmo sem a polêmica que no final das contas catapultou a bilheteria de sua obra de estréia.

Se pensarmos que a contratação de Welles para a co-direção - junto de Norman Foster - e produção do filme documental "It's All True" (que consiste numa obra alinhada politicamente à proposta do OCIAA), se dá logo em seguida à polêmica recepção que Citizen Kane tivera no âmbito do público, crítica e estúdios, que forças então levaram o "Escritório para Assuntos Interamericanos", por meio do estúdio RKO, a contratar Welles como co-diretor de um filme cujo objetivo era a construção de identidades "hermanas"?

\footnotetext{
${ }^{13}$ Por exemplo, é a opinião de Danny Peary em "Guide for the Film Fanatic": "Can justifiably be called the greatest picture of all time. Countless classic moments." Foi ainda o número 1 da lista "Best American Movies", em 1998, do "American Film Institute".

${ }^{14}$ A polêmica foi abordada no documentário "The Battle Over Citizen Kane", que venceu o Oscar na categoria documentário em 1995.
} 
Nossa hipótese é de que o objetivo do OCIAA era instrumentalizar o poder de controle social demonstrado pelos veículos de comunicação de massa quando Welles narrou a obra de H.G. Wells na transmissão radiofônica da "Guerra dos Mundos", não a crítica que empreendeu em Citizen Kane ou que propunha em Soberba. A imensa mobilização causada pela transmissão chamou a atenção dos agentes do Estado, demonstrando claramente possibilidades de sua instrumentalização política e militar, muito mais do que a inovação estética proposta em sua obra prima.

Um número significativo de pessoas havia sido convencido por notícias absurdas, e porque não utilizar os mesmos recursos para cooptá-las no interesse do Estado em tempo de guerra? Os próprios alemães, especificamente o ministro da propaganda nazista Goebbels, já haviam percebido o poder da propaganda como arma de guerra, transformando o rádio e o cinema em instrumentos dela.

Ficava demonstrado que os limites entre ficção e realidade poderiam ser gerenciados pelo Estado, segundo seus propósitos, mesmo que militares, criando realidades distorcidas.

Os interesses do Estado se sobrepuseram às tendências do mercado que já via Welles como um forte candidato ao ostracismo - em virtude da campanha movida pelo próprio Hearst para boicotar o filme e o diretor em Hollywood -, para colocá-lo ao seu serviço no esforço de guerra.

Isso explica em grande parte a vinda de Welles ao Brasil assim que terminou as filmagens de Soberba, para filmar o carnaval carioca, cujas cenas fariam parte do seguimento My Friend Bonito, do filme que tinha como tema a amizade entre um menino pobre e seu touro. 


\section{As atividades de Welles}

O Memorandum CO-948 do CIAA, datado de 27 de abril de 1942 e que relatava as atividades de Orson Welles no Brasil, demonstra que mais do que um diretor, cumpria ele uma agenda digna de um embaixador da cultura estadunidense na América Latina.

Praticamente todos os dias Welles se encontrava, oficialmente ou não, com jornalistas dos mais expressivos periódicos brasileiros e de jornais de outras repúblicas latino-americanas, além de empresários, banqueiros, literatos, acadêmicos, intelectuais, artistas de teatro, personalidades do rádio e políticos ligados ao governo brasileiro. Tornou-se ainda íntimo da família Vargas e de Osvaldo Aranha, além de amigo pessoal do interventor de Minas Gerais, Benedito Valladares.

Welles ainda viajou a Buenos Aires, onde foi recebido por membros do governo e das artes, além de conceder inúmeras entrevistas à imprensa.

De volta ao Brasil assumiu um programa diário de rádio, o que complicava ainda mais seu comprometimento com o projeto do filme.

Não se referia nessas oportunidades exclusivamente ao seu trabalho, na realidade a maior parte de suas declaraçóes estava centrada na questão da guerra e da política de integração continental proposta pelo governo dos EUA, o que corrobora a tese de que se tratava de um agente dessa política externa.

Welles deveria ser o criador da imagem do império e o operador das máquinas que a projetariam aos espectadores latino-americanos, e mostravase o porta-voz direto dessas políticas.

Tantas atribuições atrasaram o calendário do projeto e conseqüentemente aumentaram os gastos previstos, além de consolidar a crescente influência de Welles nas mais altas esferas de poder no Brasil. Mas no expediente que circulou neste período o escritório não parecia, de forma grave, preocupado com o fiel cumprimento do cronograma.

O relatório ainda informa que $85 \%$ do projeto "Carnaval" já havia sido concluído, e que os $15 \%$ restantes seriam constituídos pelo trabalho de três semanas de estúdio (da Cinédia) e da tomada de cenas do Cassino da Urca, onde boa parte da seqüência se desenrolaria, o que levaria mais 10 dias.

Depois disso metade da equipe poderia retornar à Hollywood, enquanto 
Welles e mais 5 ou 6 homens viajariam para Salvador para terminar a polêmica seqüência do "Jangadeiro", para a qual seriam necessárias de 4 a 7 semanas. Nisso consistia o problema.

A seqüência é decorrente da tomada inusitada, feita no Rio de Janeiro, de um jangadeiro que viajava em protesto à capital da República, morto por afogamento quando já estava próximo à praia.

A insistência de Welles em criar uma seqüência que não estava prevista no projeto inicial para a morte do jangadeiro, e sua relutância em desistir dela, iniciavam uma crise que culminaria na demissão de Welles.

O relatório soa entusiasmado mas demonstra que, a partir da insistência de Welles em terminar a seqüência, os problemas tanto em relação aos gastos da viagem quanto à demora para conclusão do projeto passaram a ganhar maior importância.

making a Picture in Brazil means working day and night. It means working several days on a problem which an organized studio in Hollywood could cope with in a few hours [...]. It should be clear, then, that the difficulties accompanying a major production are enormous and are impossible to overcome in a few weeks [...] [...] this means, first of all, that a full cooperative relation with official government departments and unofficial groups must be established. A double handicap a) that of experienced men ignorant of the language on one hand, and inexperienced Brazilians on the other b) must be got over.

O problema maior não aparece no relato, inscreve-se em suas entrelinhas: consiste na queda de braço que Welles iniciou com o DIP, e que perdeu.

Logo em seguida à polêmica, Soberba teve 43 minutos da edição original amputados da versão final, enquanto Welles ainda estava no Brasil. O fracasso de bilheteria foi o argumento utilizado para sua demissão bem como de toda a sua equipe.

Sua visão crítica, que não aparecia na seqüência "Carnaval” mas em "Jangadeiro", não interessava ao Escritório, muito menos o mal estar que resultava com o DIP e o Estado Novo.

A inserção que conseguiu nas esferas governamentais não impediu que 
com "Jangadeiro" Welles passasse a constituir uma ameaça à aproximação entre Brasil e EUA.

Quando a crítica não pôde mais ser anulada, quando Welles não desistiu da seqüência e bateu de frente com as diretrizes do OCIAA, caiu em desgraça nas políticas do Escritório.

It's All True ficou inacabado.

\section{Relações possíveis entre as políticas do OCIAA, as iniciativas de Welles e seu desligamento}

Não basta dizer que o OCIAA e o DIP mantinham íntimas relaçóes, a correspondência oficial de Lourival Fontes, Diretor-Geral do departamento, endereçada a John Hay Whitney, demonstra mais do que intimidade, demonstra o que o próprio governo brasileiro esperava do cinema hollywoodiano.

Para o diretor,

[...] o que mais nos agradaria seriam filmes produzidos sobre assuntos brasileiros, nos Estados Unidos ou no Brasil. Com artistas americanos e, quando possível, com o emprego de alguns elementos brasileiros. A principal fonte a explorar, nesse terreno, seriam os episódios ligados à nossa história, como, por exemplo, a epopéia dos Bandeirantes, os episódios da catequese pelos jesuítas as lutas de independência, (como a Inconfidência Mineira), os episódios da corte de D. João VI, de D. Pedro I e de D. Pedro II, que póem em relevo o espírito nacional brasileiro.

Sobre o papel dos censores do DIP o diretor diz que,

[...] A censura é exercida da maneira mais benévola possível (sic). São raros os casos de interdição de filmes (sic). A lei da Censura estabelece como causas para a interdição: a) filmes que incitam a rebeliáo das massas, ao desrespeito às autoridades, à greve e ao terrorismo e sabotagem; b) os que contêm insulto a chefes de Estado estrangeiros e a credos religiosos, ou que constituam ofensa aos sentimentos nacionais; 
c) os que induzam ao desregramento e à dissolução social.

Definitivamente, jangadeiros morrendo em protesto contra as políticas do Estado Novo não interessavam ao DIP, por incitarem as massas, o desrespeito às autoridades e o desregramento social, segundo sua concepção de censura para protestos populares. Não interessava evidentemente à OCIAA, por ameaçar a frágil aproximação do governo dos EUA e seu esforço defensivo com um regime declaradamente simpático aos fascismos europeus (uma demonstração pública de simpatia ao fascismo ocorreu no discurso proferido durante o almoço de comemoração do dia da Marinha do Brasil, a bordo do "Minas Gerais", em companhia do alto escalão das armas brasileiras no dia 11 de junho de 1940; sua transcrição foi publicada em Barros e Faria, (1984, p. 89-92).

O diretor-geral do DIP tinha a receita para o que deveria constituir os temas dos filmes realizados por Hollywood no Brasil, para ele,

[...] o público brasileiro se interessa grandemente pelos filmes de reconstituiçáo histórica e pelas películas culturais, como os "tapetes mágicos" e "Viagens" de Fitzpatrick, etc.

Nessa concepção, este tipo de protesto não constituía a imagem de Brasil que o Estado Novo gostaria que fosse projetada pelo cinema hollywoodiano. Sua sugestão a John Hay Withney para elevar o "nível cultural das massas" são:

a) filmes sobre as grandes quedas dágua do Brasil, como Iguassú, Avanhandava e Paulo Afonso;

b) sôbre a região amazônica: rios, fauna e flora;

c) a extraçáo de quartzo, em Minas Gerais (material estratégico de que o Brasil é o maior e quasi (sic) único produtor mundial);

d) experiências brasileiras sobre o ofidismo e o Instituto Butantan;

e) o Instituto de Manguinhos, grande centro de estudos de moléstias tropicais, mantido pelo governo do Brasil;

f) arte religiosa de Minas Gerais e obras do Aleijadinho;

g) o problema das secas do Nordeste Brasileiro e as grandes obras realizadas para combatê-las; 
h) a extração de cera de carnaúba (de tâo emprego na indústria americana) nas regióes do Nordeste;

i) a vida dos jangadeiros;

j) a vida dos "gaúchos" nas fazendas do Rio Grande do Sul;

1) as lavras diamantíferas de Minas Gerais e Mato Grosso;

m) a lavra do ouro e as minas (São João Del Rey, Mining Co., Morro Velho, etc.) (grifos nossos)

No Brasil que o Estado Novo queria fazer acreditar que existisse não havia restriçóes sociais, luta de classes, protestos desesperados nem jangadeiros morrendo, havia o gigantismo de um país cujo território de proporçóes continentais era dono de uma natureza monumental e de recursos ilimitados, havia fonte de riqueza e recursos prontos para serem explorados pela indústria dos países capitalistas mais desenvolvidos, havia um repertório de monumentos que denotavam um modelo de nação, e havia uma história que exaltava o colonizador como detentor do fardo civilizador por um lado e heroicizava mártires libertários por outro.

Para o diretor de um dos mais violentos órgãos de censura, de um dos negros períodos de ditadura no Brasil, os temas elencados "[...] fixam problemas de real importância e ligados à defesa comum das Américas”.

Sobre Walt Disney o próprio Osvaldo Aranha declarou que a exibição de "Fantasia" deveria ser obrigatória; sobre Orson Wells, o até ali amigo Aranha nada mais dizia.

Depois de assistir à Fantasia e Alô Amigos fica claro que Disney era a pessoa certa segundo os propósitos do OCIAA. Depois de ver Citzen Kane e o que restou de It's All True de Wells, incluindo a seqüência "Jangadeiro" (material disponível no Centro de Apoio à Pesquisa Histórica do Departamento de História da Universidade de São Paulo), pensamos que definitivamente o OCIAA, de acordo com os seus propósitos, enviou a pessoa errada! 


\section{Conclusões}

O período da Segunda Guerra Mundial foi fundamental para a consolidação da indústria cinematográfica estadunidense como líder do mercado cinematográfico mundial. Não apenas isso, sua instrumentalização política no contexto da guerra fez difundir valores e imagens de modernização, resultando nos países periféricos a implementação de modernizaçôes abstratas e um estado catatônico de estupefação.

Estava inaugurado o período de imperialismo cultural, mas que não havia sido extirpado de sua dimensão política e econômica.

No momento imediato do pós-guerra este imperialismo cultural fio exercido pela via política, por meio da inclusão de cláusulas aquisitivas de "enlatados culturais" em tratados e pacotes de auxílio econômico.

O potencial demonstrado pelos veículos de comunicação de massa na construção da realidade social e de suas imagens consolidou-se de forma irreversível como política de Estado no Plano Marshall, e sua nova instrumentalização política e militar no contexto da Guerra Fria demonstram que a eficácia desta arma de guerra e seu poder de sedução já haviam sido constatados durante a Segunda Guerra Mundial.

Disney e Welles foram instrumentos desta lógica, os gatilhos que acionados pelo Estado fariam funcionar a arma. Disney cumpriu fielmente sua missão como agente da política de boa vizinhança de Roosevelt; Welles foi o gatilho que tomou consciência de si mesmo e deliberadamente emperrou, motivo pelo qual foi substituído por outros agentes, conscientes ou não de seu papel naquele contexto. 


\section{Referências Bibliográficas}

BARBIER, Christophe. As muitas vidas do papai Walt Disney. O Estado de São Paulo, São Paulo, 14 out. 2001.

BARROS, Edgard Luiz; FARIA, Antonio Augusto. O retrato do velho. São Paulo: Atual, 1984.

DORFMAN, Ariel; MATTELART, Armand. Para ler o Pato Donald. São Paulo: Paz e Terra, 1980.

ELIOT, Marc. Walt Disney: o príncipe sombrio de Hollywood. São Paulo: Marco Zero, 1993.

FRANCO, Maria Sylvia de Carvalho. As idéias estão no lugar. Cadernos de Debate, História do Brasil, São Paulo, Brasiliense, 1976.

HILTON, Stanley. A guerra secreta de Hitler no Brasil. São Paulo: Nova Fronteira, 1983.

JAMESON, Fredric. A cultura do dinheiro. Petrópolis: Vozes, 2001.

LEITE, Sidney Ferreira. Cinema brasileiro: das origens à retomada. São Paulo: Perseu Abramo, 2005.

. Um pouco de malandragem. História Viva, n. 30, abril de 2006. Disponível em: http://www2.uol.com.br/historiaviva/conteudo/materia_ imprimir_65.html. Acesso em: 9 abr. 2006.

MOURA, Gerson. Tio Sam chega ao Brasil: a penetração cultural americana. São Paulo, 1983.

RODÓ, José Enrique. Ariel. Montevideo: Colombino Hnos, 1947.

SADER, Emir. Civilização ou barbárie. Correio Icarabe, Instituto da Cultura Árabe, ano 2, n. 39, 24 fev./2 mar. 2006.

SILVA, Hélio. Guerra inevitável (1939-1942). São Paulo: Editora Três, 1975. 